\title{
DISPARITY IN ADOPTION OF WHEAT PRODUCTION TECHNOLOGY PACKAGES IN EASTERN ETHIOPIA
}

\author{
Degefu KEBEDE ${ }^{1 *}$, Mengistu KETEMA ${ }^{1}$, Nigussie DECHASSA ${ }^{2}$
}

\author{
Address: \\ ${ }^{1}$ School of Agricultural Economics and Agribusiness, Haramaya University, Ethiopia \\ ${ }^{2}$ School of Plant Sciences, Haramaya University, Ethiopia \\ * Corresponding author: dgfkebede2009@gmail.com
}

\begin{abstract}
Production of wheat by smallholder farmers in Ethiopia contributes a significant share to the agricultural production of the country. However, the actual productivity of the crop has been far below its potential. Varied levels of technology adoption are often observed among smallholder farmers producing the crop. For enhanced dissemination of technology packages and improving wheat productivity, it is vital to elucidate socio-economic factors that are behind disparity in technology adaption among smallholder farmers. Therefore, this study was conducted to analyse the socioeconomic, institutional, and other pertinent variables that determine the existing disparity observed among smallholder farmers in terms of adopting wheat production technology packages in Gurawa and Meta districts of eastern Ethiopia. The study utilized survey data collected from 124 randomly selected wheat households producing wheat. For this purpose, an ordered logit model was applied. The econometric results revealed that age of the household head, membership in cooperative institutions, and household annual income significantly and positively explained the disparity observed in adoption of wheat production technology packages. Conversely, gender of household head (sex), farming experiences, number of plots owned, and frequency of contacts with extension agents explained the disparity significantly, but negatively. It could be concluded that development practitioners, planners, and policy makers should give due considerations to the aforementioned socio-economic and institutional factors when designing dissemination of wheat production technology packages for adoption by farmers.
\end{abstract}

Keywords: disparity in technology adoption, ordered logit, smallholder farmers, socio-economic factors, wheat technology package

JEL: D13, Q12

\section{INTRODUCTION}

More than $85 \%$ of the Ethiopian people depend on agriculture for their livelihood. The sector also contributes $38.8 \%$ to the Gross Domestic Product and takes a major share in export earnings where exports of coffee, oilseeds, khat (Mild stimulant crop, Chata edulis Forsk), leather and leather products, pulses, and flower alone contribute more than $70 \%$ (NBE, 2016).

Ethiopia is among the countries endowed with diverse agro-ecology which is suitable for agricultural production. Moreover, the country has made remarkable efforts in increasing productivity of the sector through devising various policies and strategies (Bingxin et al., 2011; Bachewe et al., 2015), mainly targeting to improve agricultural performance through adoption of improved agricultural technologies. However, despite these efforts, the sector's productivity has remained low for several reasons, among which low level of agricultural technology adoption is one (Million, 2010; Spielman et al., 2010; Ortiz et al., 2013; Abebe et al. 2013; Mengistu et al., 2016; Degefu et al., 2017).

Prior empirical studies investigated determinants of adoption of crop technologies, wheat technology adoption inclusive, in terms of adopting a single technology component or package-based components. For instance, Hirpa et al. (2010) indicated that lack of improved varieties along with the other recommended technology packages is a bottleneck for enhancing potato production in Ethiopia. In a similar study, Rao and Debela (2016) concluded that the use of fertilizers for crop production remained low. Million (2014) showed that farmers applied both organic and inorganic fertilizers, but the use of inorganic fertilizers was low. Other studies also indicated that adoption of inorganic fertilizers such as DAP and Urea in crop production is governed by a number of factors including location, household socio-economic status, and institutional factors (Mengistu and Degefu, 2017; Degefu and Mengistu, 2017).

Empirical studies on package-based crop technology adoption also revealed variations depending on areas of study, gender, age of the household head, access to irrigation, education status of the household head, farm size, distance to market, distance to FTC (Farmers' Training Centers), cooperative membership, dependency ratio and annual income of the households significantly affected the adoption of crop technology packages 
(Mengistu et al., 2016, Degefu et al., 2017).

By and large, factors explaining adoption of crop technologies were found to be socio-economic and institutional factors (Mengistu et al., 2016, Degefu et al., 2017), technical knowledge (Legese et al., 2009; Mengistu and Bauer, 2011), and high costs (Endale, 2011; Tufa et al., 2015). Though many crop technology adoption studies investigated the reason behind low level of adoption of agricultural technologies in general and crop technologies in particular (Shiferaw et al., 2014; Beshir, 2016; Biftu and Diriba, 2016; Kaleb, 2017), it is necessary to elicit concrete data through empirical studies in this regard. This is because the factors are not universal, but are rather context-specific and dynamic within the farming community through time in terms of socioeconomic and other variables (Ogada et al., 2014; Rao and Debela, 2016).

Moreover, the reasons behind why some farmers are low adopters while others are medium and high adopters of the same technology package in wheat production under smallholder farmers' context have not been adequately investigated. Moreover, in an attempt to address the policy variables that influence adoption of wheat technology packages, it is important to elucidate the factors that cause the disparity in adoption of wheat technology packages as low, medium, higher adopter's category). Without singling out the adoption disparity factors, the effectiveness of policy actions to enhance productivity of the crop will remain low especially in terms of addressing the adoption level along with the speed of diffusion of technologies among smallholder farmers.

It is, therefore, essential to investigate whether the socio-economic and institutional factors, along with other pertinent determinants govern the disparity observed among smallholder farmers in terms of adopting wheat technology packages, taking in to account the low, medium and high adopter categories in two districts of eastern Ethiopia.

\section{DATA AND METHODS}

\section{Description of the Study Area}

The study was conducted in two districts of eastern Hararghe zone in eastern Ethiopia, namely, Gurawa and Meta. These districts are known for high agricultural production potential. Major crops grown in the districts include staple crops (wheat, barley, tef, maize, sorghum, and Irish potato) as well as a cash crop such as coffee (Nigussie Dechassa et al., 2012).

In terms of altitude, both districts have areas that range from low to high. Regarding elevation for example, the altitude of Gurawa ranges from 500 to 3230 meters above sea level. According to the Central Statistical Agency (CSA, 2013), an estimated projected total population for the year 2017 shows that the total populations of Gurawa and Meta district are 307464 and 326035 , respectively. In the study areas, livestock feed is among the major problem constraining agricultural production mainly due to shortage of as well as a result of the fact that crop residues are removed from farmlands immediately after harvest for use as firewood (Nigussie
Dechassa et al., 2012).

Wheat is an important cereal crop in eastern Hararghe zone, where Gurawa and Meta districts are located. The total area under wheat production in the zone is 18289.94 ha (CSA, 2016). The zonal average productivity of the crop is 2.1 tons/ha, which is less than the national average yield of 2.5 tons/ha (CSA, 2015). The figure is by far less than the world average of 3.05 tons/ha for the year 2014/15 (Statista, 2017), which implies a low level of adoption of wheat production technology packages in the area.

\section{Sampling Procedure}

The study utilized data collected through a crosssectional study design. A household survey questionnaire was administered to collect primary data from the smallholder farmers drawn from the aforementioned study districts. A multi-stage sampling technique was employed where the steps involved purposive selection of the two districts, followed by a random selection of two representative kebeles (kebele is the smallest administrative unit in Ethiopia) from each district making a total of four kebeles. As final respondents, a total of 124 randomly selected household heads were taken from a population of wheat growing farmers in the selected kebeles.

\section{Data Sources and Methods of Data Collection}

Household socio-economic characteristics, farm characteristics, institutional factors, use of improved wheat production packages such as row planting, uses of improved varieties, inorganic fertilizers, pesticides , and primary data on other pertinent variables were collected using the structured questionnaire during the 2015/2016 cropping season. Moreover, additional information on recommended inorganic fertilizer rates were collected from secondary sources in order to compute the fertilizer use intensity so as to drive adoption index as a proxy for the technology package adopter category.

\section{Specification of Econometric Model}

The nature of dependent variables is a directive for the selection of appropriate econometrics model. The dependent variable in this study is adopters' category which is based on computed adoption index from various technology adoption proxies. Accordingly, low adopters, medium adopters, and high adopters were the three categories of adopters based on the index value categorization. The category bears three ordered values $(0,0.5$ and 1$)$ evaluated at the standard deviation from the mean as a cut-off points. Hence, observations with the value of " 0 " signify low adopter category, 0.5 signify medium adopter category, while those with the value of "1.0" signify high adopter category.

The adoption indices for wheat technology package were initially computed from five technology components, including uses of row planting, pesticides application, use intensities of DAP, urea, and improved wheat varieties. Thus, values $0,0.5$ and 1.0 indicate the level of the adoption within the three values of the ordered logit model of the low, medium and higher adopter categories, respectively. 
Ordered logit model is used to estimate relationships between an ordinal dependent variable and a set of predictor variables. By definition, an ordinal variable is a variable that is categorical and ordered. In ordered logit, an underlying score is estimated as a linear function of the predictor variables and a set of cut points (StataCorp, 2011; Long and Freese, 2014). The probability of observing outcome $i$ corresponds to the probability that the estimated linear function, plus random error, is within the range of the cut points estimated for the outcome (Eq. 1).

$$
\begin{aligned}
& p_{i j}=\operatorname{Pr}\left(y_{j}=i\right)=\operatorname{Pr}\left(k_{i-1}<x_{j} \beta+u \leq k_{i}\right)= \\
& \frac{1}{1+\exp \left(-k_{i}+x_{j} \beta\right)}-\frac{1}{1+\exp \left(-k_{i}-1+x_{j} \beta\right)}
\end{aligned}
$$

Where, $u_{j}$ is assumed to be logistically distributed in ordered logit and the coefficients of $\beta\left(\beta_{1}, \beta_{2}, \ldots, \beta_{k}\right)$ along with the cut points $\mathrm{k}_{1}, \mathrm{k}_{2} \ldots, \mathrm{k}_{\mathrm{k}-1}$, where $\mathrm{k}$ is the number of possible outcomes. The value of $\mathrm{k}_{0}$ is defined as $-\infty$, and $\mathrm{k}_{\mathrm{k}}$ as $+\infty$ (Kosuke et al., 2007, StataCorp, 2011). The coefficients and cut points are estimated using maximum likelihood and in the parameterization, no constant appears, because the effect is absorbed into the cut points.

The estimates of ordered logit indicate the relationship between the predictor variables and the dependent variable, where the dependent variable is on the logit scale. Because of the fact that the coefficients of the estimates are in log-odds units, they are often difficult to interpret, so they are often converted into odds ratios (StataCorp, 2011). Based on theoretical justifications and prior literature, a number of predictor variables have been hypothesized to explain the disparities in adoption level of wheat technology package among wheat growing smallholders.

\section{Definition of Variables and Working Hypotheses}

The dependent variable was the index value of wheat technology packages in three categories of adopters. The categorization of the three categories of adopters was based on the mean and the standard deviation of the index value from the sample mean of the observations. Accordingly, the first category, i.e. the low adopter, was the observation having values of the index less than or equal to the difference between the mean and the standard deviation. Similarly, the second category, i.e. the medium or partial adopter categories were observations having value of the index between the difference in mean and standard deviation (i.e upper limit of low adopters), and the values of the sum of mean and standard deviation (i.e lower limit of high adopters). The third category of higher adoption was any observation having an index value of higher than or equal to the sum of mean and standard deviation.

Moreover, in order to run the ordered logit model, the index values were censored to have three values 0 , 0.5 and 1.0 as per the aforementioned classifications of the adopter categories. Hence, the computation of the index category was a representation for low (less than or equals to $23 \%$ ), medium (between $23 \%$ and $71 \%$ ), and high (greater than or equals to $71 \%$ ) category of wheat technology package in that order. It has to be noticed that the mean of the index was found to be 0.47 with a standard deviation of 0.24 . Table 1 indicates lists of predictor variables hypothesized to affect ordered ranks of technology package adopters in wheat production.

\section{RESULTS AND DISCUSSION}

\section{Descriptive Results}

On average, about $97 \%$ of the respondents were maleheaded low adopter households whereas about $3.0 \%$ were female-headed low adopter households. For medium and high adopters, about $93 \%$ and $87 \%$ were male headed and about $7.0 \%$ and $13 \%$ were female-headed households in the order listed here. Overall, about $91 \%$ were maleheaded households and the remaining $9.0 \%$ were femaleheaded households (Table 2). These are indications that adopters category varied with gender, as most importantly, females play a key role in most agricultural systems. Hence, failure to consider this part of the farming population may result in a technology transfer bias.

Results for the literacy variable showed that about $58 \%, 59 \%$, and $79 \%$ of the technology adopters were illiterate for low adopter, medium adopter, and high adopter categories in the order described here. In addition, for the pooled observation, the literacy status is about $69 \%$. In general, the differences in literacy variable among the three categories of adopter was statistically significant $(\mathrm{p}<0.05)$ with $\chi^{2}$-value of 6.33 (Table 2 ).

The results revealed that about $38 \%$ of the low adopter respondents had extension contacts on a monthly basis at most. On the other hand, 28\% of this adopter's category farmers had a weekly basis contacts and the same proportion had extension contacts on a fortnight basis, and about $3.0 \%$ had on a daily basis. In addition, the remaining $3.0 \%$ had no extension contact at all. Under medium adopters' category, about $36 \%, 28 \%$, and $20 \%$ of the farmers had extension contacts on a monthly, weekly, and fortnightly basis, respectively (see Table 2 for high adopter's category).

On average, about 59\% of the high adopter households were members of cooperative institutions while cooperative membership was as low as $36 \%$ and $21 \%$ for low adopter and medium adopter categories, respectively. Hence, membership a household in a cooperative resulted in a statistically significant difference $(\mathrm{p}<0.01)$ among the three groups with $\chi^{2}$ value of 12.17 (Table 2 ).

The average age of sample household heads was 36.52 years for low adopters, 37.03 years for medium adopters, and 40.31 years for high adopters. The average family size in the study areas was six for the low adopter category whilst it was seven for both medium and high adopter categories (Table 3). The results for the farming experience showed that high adopter category had experiences of about 20 years whereas the medium and low adopter categories had farming experiences of 19 and 18 years, respectively.

Average land holding is in general low in the study 
areas where it is only about $0.34,0.34$, and 0.43 ha for low, medium, and high adopters in the order mentioned here (Table 3). In addition, livestock ownership in Total
Livestock Holding Units (TLU) was about 4.64, 4.37, and 3.91 on average for high, low, and medium adopter sample households in the order mentioned here.

Table 1. Summary of the predictor variables in adopters' category of wheat technology package adoption

\begin{tabular}{|c|c|c|c|}
\hline Variables & $\begin{array}{l}\text { Type of } \\
\text { Variable }\end{array}$ & Description of the variable & $\begin{array}{l}\text { Expected } \\
\text { sign }\end{array}$ \\
\hline \multicolumn{4}{|l|}{ Dependent variable } \\
\hline Index of technology converted into adopters' category & Ordinal & $\begin{array}{l}\text { Ordinal value representing low, } \\
\text { medium and higher adopters } \\
\text { category }\end{array}$ & None \\
\hline \multicolumn{4}{|l|}{ Independent variables } \\
\hline Sex of the HH head & Dummy & 1 if the head is male, 0 otherwise & $+/-$ \\
\hline Age & Continuous & Age of household head (in years) & + \\
\hline Education of household head & Dummy & 0 if illiterate, 1 otherwise & + \\
\hline Family size & Discrete & $\begin{array}{l}\text { Number of individuals in a } \\
\text { household }\end{array}$ & $+/-$ \\
\hline Farming experience & Continuous & $\begin{array}{l}\text { Household head's farm experience } \\
\text { in years }\end{array}$ & + \\
\hline Distance to market & Continuous & Distance from market in $\mathrm{Km}$ & - \\
\hline Distance from FTC & Continuous & Distance from FTC in $\mathrm{Km}$ & - \\
\hline Total land size & Continuous & Total land size in ha & + \\
\hline Number of plots & Discrete & Number of plots owned & $+/-$ \\
\hline Frequencies of extension contact & Categorical & $\begin{array}{l}\text { Frequencies of extension contact: a } \\
\text { value } 0,1,2,3,4 \text { and } 5 \text { for no } \\
\text { contact, every day, every week, } \\
\text { every fortnight, and every month, } \\
\text { respectively }\end{array}$ & $+/-$ \\
\hline Membership in cooperatives & Dummy & $1=$ if member, 0 otherwise & + \\
\hline Livestock ownership & Continuous & $\begin{array}{l}\text { Livestock holding in tropical } \\
\text { livestock units }\end{array}$ & + \\
\hline Dependency ratio & Continuous & $\begin{array}{l}\text { The ratio of dependent members to } \\
\text { active members }\end{array}$ & - \\
\hline Annual income (Birr. '000’) & Continuous & $\begin{array}{l}\text { Annual income in ETB from crops, } \\
\text { livestock, and off farm activities }\end{array}$ & + \\
\hline
\end{tabular}

Table 2: Summary statistics of the sample households (categorical variables) (\%)

\begin{tabular}{|c|c|c|c|c|c|c|c|c|c|}
\hline \multirow{3}{*}{ Variables } & \multicolumn{9}{|c|}{ Adopters category } \\
\hline & \multicolumn{2}{|c|}{ Low adopters } & \multicolumn{2}{|c|}{ Medium adopters } & \multicolumn{2}{|c|}{ High adopters } & \multicolumn{2}{|c|}{ Pooled } & \multirow[t]{2}{*}{$\chi^{2}$-value } \\
\hline & $\mathrm{n}$ & $\%$ & $\mathrm{n}$ & $\%$ & $\mathrm{n}$ & $\%$ & $\mathrm{n}$ & $\%$ & \\
\hline \multicolumn{10}{|l|}{ Survey districts } \\
\hline Gurawa & 12 & 36.36 & 11 & 37.93 & 28 & 45.16 & 51 & 41.13 & \multirow{2}{*}{0.85} \\
\hline Meta & 21 & 63.64 & 18 & 62.07 & 34 & 54.84 & 73 & 58.87 & \\
\hline \multicolumn{10}{|c|}{ Sex of household head } \\
\hline Female & 1 & 3.03 & 2 & 6.90 & 8 & 12.90 & 11 & 8.87 & \multirow[t]{2}{*}{2.78} \\
\hline Male & 32 & 96.97 & 27 & 93.10 & 54 & 87.10 & 113 & 91.13 & \\
\hline \multicolumn{10}{|c|}{ Education of household head } \\
\hline Illiterate & 14 & 42.42 & 12 & 41.38 & 13 & 20.97 & 39 & 31.45 & \multirow[t]{2}{*}{$6.33 * *$} \\
\hline Literate & 19 & 57.58 & 17 & 58.62 & 49 & 79.03 & 85 & 68.55 & \\
\hline \multicolumn{10}{|c|}{ Frequencies of extension contact } \\
\hline No contact & 1 & 3.45 & 1 & 4.00 & 1 & 1.75 & 3 & 2.70 & \multirow[t]{5}{*}{4.94} \\
\hline Every day & 1 & 3.45 & 3 & 12.00 & 3 & 5.26 & 7 & 6.31 & \\
\hline Every week & 8 & 27.59 & 7 & 28.00 & 10 & 17.54 & 25 & 22.52 & \\
\hline Every fortnight & 8 & 27.59 & 5 & 20.00 & 20 & 35.09 & 33 & 29.73 & \\
\hline Every month & 11 & 37.93 & 9 & 36.00 & 23 & 40.35 & 43 & 38.74 & \\
\hline \multicolumn{10}{|c|}{ Membership to cooperative } \\
\hline Non member & 21 & 63.64 & 23 & 79.31 & 26 & 41.94 & 70 & 56.45 & \multirow[t]{2}{*}{$12.17 * * *$} \\
\hline Member & 12 & 36.36 & 6 & 20.69 & 36 & 58.06 & 54 & 43.55 & \\
\hline
\end{tabular}

*** and ** implies statistically significant at $1 \%$ \& 5\% levels, respectively 
Table 3: Summary statistics of the sample households (continuous variables) (Mean \& SD)

\begin{tabular}{|c|c|c|c|c|}
\hline \multirow[b]{2}{*}{ Variables } & \multicolumn{4}{|c|}{ Wheat technology package adopters category } \\
\hline & $\begin{array}{l}\text { Low adopters } \\
(\mathrm{n}=33)\end{array}$ & $\begin{array}{l}\text { Medium adopters } \\
(\mathrm{n}=29)\end{array}$ & $\begin{array}{l}\text { High adopters } \\
(n=62)\end{array}$ & $\begin{array}{l}\text { Pooled } \\
(\mathrm{n}=124)\end{array}$ \\
\hline Age (years) & $36.52(9.2)$ & $37.03(8.1)$ & $40.31(10.3)$ & $38.53(9.7)$ \\
\hline Family size & $5.94(1.3)$ & $6.69(2.2)$ & $6.81(2.5)$ & $6.55(2.2)$ \\
\hline Farming experience (years) & $17.77(8.3)$ & $18.66(7.8)$ & $19.56(9.1)$ & $18.87(8.6)$ \\
\hline Distance to market $(\mathrm{km})$ & $4.20(1.4)$ & $3.16(2.2)$ & $3.44(2.3)$ & $3.58(2.1)$ \\
\hline Distance from FTC $(\mathrm{km})$ & $1.54(1.3)$ & $1.21(1.2)$ & $2.03(2.3)$ & $1.71(1.8)$ \\
\hline Total land size (ha) & $0.34(0.2)$ & $0.34(0.2)$ & $0.43(0.3)$ & $0.39(0.2)$ \\
\hline Number of plots & $2.85(1.1)$ & $2.66(0.8)$ & $2.77(1.2)$ & $2.78(1.1)$ \\
\hline Livestock ownership (TLU) & $4.37(3.4)$ & $3.91(2.7)$ & $4.64(3.3)$ & $4.39(3.2)$ \\
\hline Dependency ratio & $1.28(0.9)$ & $1.34(0.9)$ & $1.26(0.7)$ & $1.29(0.8)$ \\
\hline Annual income (000' Birr) & $12.28(9.1)$ & $13.25(10.3)$ & $18.97(12.5)$ & $15.85(11.5)$ \\
\hline
\end{tabular}

Figures in parenthesis indicate standard deviation; $\mathrm{SD}=$ Standard Deviation

In terms of income, households in high adopter category earned a higher income (about 18,970 Birr per year), followed by those in medium adopters (about 13,250 Birr per year), and low adopters (about 12,280 Birr per year).

Moreover, low adopters had their residences within a distance of about four kilometers from market centers whereas both the low and medium adopters had their residences with a distance of about less than four kilometers from the market center.

\section{Econometric Estimates of Disparity Factors in Smallholders' Adoption Level}

The ordered logit model estimate result for factors behind the disparity of adoption of wheat technology package indicated a good fit at $1 \%$ level of significance (Table 4). In addition, the overall variance inflation factors (VIF) of all explanatory variables in the model was found to be less than 10 , depicting that multicollinearity was not a severe problem in the estimate. The model output for the disparity factors indicated that among the variables hypothesized in the model, sex of the household head, age, number of plots owned, belonging to a cooperative as a member and annual income were found to significantly explain the disparity levels of technology adoption among wheat producing farmers.

Sex of household head was found to be a significantly determining factor in the disparity of adopting wheat production technology packages observed among smallholder farmers. The result is statistically significant at $1 \%$ level of significance. According to the model estimate, keeping other factors constant, for males, the odds of being in a high adopter technology package category versus the combined medium and low adopter package are 0.05 times lower than that for females. Similarly, the odds of the combined categories of high and medium adopter's category of the package adopters versus low adopters category is 0.05 times lower for males compared to females, keeping other factors constant. This could be due to the fact that some of the technologies by their nature fit with a particular gender group under certain circumstances. This finding is consistent with that of Asfaw et al. (2012) and Degefu et al. (2017) who found that female headed households, in comparison with male headed households, were adopters of agricultural technologies.
Age of household head was found to be a significant factor governing the disparity in adoption level of the technology package. The result for the estimate revealed that keeping other factors constant, as the age of the household heads increased by a year; the respective ordered log-odds of being in a higher adopter's category also increased by about 1.13 . In the same way, for a oneyear increase in the age, the odds of the combined high and medium adopter's category versus low adopter's category of the technology package level were about 1.13 times greater, keeping the other predictor variables constant. The result is statistically significant at 5\% level of significance. This could be associated with the fact that as the farmers are getting older, there could be a capitalization of information and knowledge about the technology packages. This finding is in line with that of Hagos (2016), Kaleb and Workneh (2016), and Degefu et al. (2017) who reported that age has a positive impact on technology adoption.

A proxy for plot fragmentation, number of plots owned by the smallholders, was found to determine the disparity of adoption of technology package in wheat production. The model result showed that keeping other factors constant, for an increase in ownership of one more plot, the odds of high adopters category of the package versus the combined medium and low adopters of the package categories were 0.58 times lower. Likewise, for an increase in ownership of one more plot, the odds of the combined high and medium adopters of the technology package versus low adopters was 0.58 times lower, when the other predictor variables were kept constant.

Frequencies of contact of extension personnel of wheat producing farmers were found to negatively and significantly explain the disparity of smallholder farmer's adoption of technology package for wheat production. The model result depicts that for wheat producing farmers who had contact with extension personnel every day, the odds of high adopter's technology package category versus the combined medium and low adopters of the package were 0.12 times lower than for farmers who had no contact with extension personnel, keeping other factors constant. Similarly, the odds of the combined categories of high and medium adopter's category of the package versus low adopters category is 
0.12 times lower for farmers who had every day contact with extension personnel compared to those farmers who had no contact with extension personnel, given that the other variables in the model were kept constant. For the other frequencies of contact of extension personnel with the farmers, other than every day contact frequency, however, under this study, there is no sufficient statistical evidence that explained the relationship. This could happen due to giving less emphasis to wheat technology package or overlooking wheat technology package (while particularly more attentions may have been given to other crop technology packages by the extension personnel in advising different categories of smallholder farmers in the study area.

Membership in a cooperative, on the other hand, positively and significantly influenced the disparity of the smallholder farmers' adoption of the wheat production technology packages. Accordingly, keeping other factors constant, being a member of a cooperative institution, as compared to being a non-member, the odds of high adopter's technology package category versus the combined medium and low adopters of the package are 2.47 times higher. Similarly, the odds of the combined categories of high and medium adopter category of the package adopters versus low adopters category is 2.47 times higher for the members than the non-members, keeping other factors constant. This could be an acknowledgement of the fact that cooperatives play a significant role in determining the adoption category of the smallholders. It could be through accessing information, inputs, and ways to market their produce with cooperatives, which could have in turn, determined the disparity of agricultural technology adoption. Similar results were reported by Abebaw and Haile (2013), Mengistu et al. (2016), Mengistu and Degefu (2017), and Degefu et al. (2017).

The model output for annual income revealed that it was among the adoption disparity factors of the technology package in wheat production. The result is statistically significant at $5 \%$ level of significance. Thus, keeping other factors constant, by one Birr increase in income of the household, the respective odds of being in the higher adopter category would increase by 1.05 . Likewise, for one Birr increase in the household income, the odds of the combined high and medium adopter categories versus low adopter category of the technology package level were 1.05 times greater, keeping other disparity factors constant. This happens perhaps due to the fact that a household with adequate annual income could not be financially constrained to seek and use wheat technology packages in time. In one or the other way, this finding is congruent with the results by Degefu et al. (2016) who found a significant and positive effect of income on adoption of wheat technology packages. Similarly, the result is in line with findings by Mengistu and Degefu (2017) who found that annual income significantly determined intensity of adoption of the inorganic fertilizer urea.

Table 4. Parameter estimates of the ordered logit model

\begin{tabular}{|c|c|c|c|c|c|}
\hline \multirow[t]{2}{*}{ Predictor variables } & \multicolumn{3}{|l|}{ Coefficient } & \multicolumn{2}{|l|}{ Odds ratio } \\
\hline & Coefficient & SE (Robust) & t-value & Odds ratio & SE (Robust) \\
\hline Sex of the HH head & $-2.924 * * *$ & 0.69 & -4.21 & $0.054 * * *$ & 0.04 \\
\hline Age & $0.118 * *$ & 0.05 & 2.44 & $1.126^{* *}$ & 0.05 \\
\hline Education status & 0.699 & 0.49 & 1.43 & 2.013 & 0.98 \\
\hline Family size & 0.182 & 0.14 & 1.34 & 1.199 & 0.16 \\
\hline Farming experience & -0.063 & 0.05 & -1.17 & 0.939 & 0.05 \\
\hline Distance to market & -0.199 & 0.13 & -1.50 & 0.819 & 0.12 \\
\hline Distance from FTC & 0.157 & 0.19 & 0.83 & 1.170 & 0.22 \\
\hline Total land size & 2.409 & 1.66 & 1.45 & 11.126 & 18.44 \\
\hline Number of plots & $-0.543^{*}$ & 0.32 & -1.72 & $0.581 *$ & 0.18 \\
\hline \multicolumn{6}{|c|}{ Frequencies of extension contact (No contact is a reference group) } \\
\hline Every day & $-2.091 *$ & 1.17 & -1.78 & $0.124 *$ & 0.14 \\
\hline Every week & -0.647 & 1.07 & -0.60 & 0.523 & 0.56 \\
\hline Every fortnight & 0.127 & 1.06 & 0.12 & 1.136 & 1.21 \\
\hline Every month & -0.566 & 1.09 & -0.52 & 0.568 & 0.62 \\
\hline Membership to cooperative & $0.906^{*}$ & 0.49 & 1.84 & $2.473^{*}$ & 1.22 \\
\hline Livestock ownership & -0.004 & 0.12 & -0.04 & 0.996 & 0.12 \\
\hline Dependency ratio & 0.336 & 0.32 & 1.05 & 1.399 & 0.45 \\
\hline Annual income & $0.048 * *$ & 0.02 & 2.11 & $1.049 * *$ & 0.02 \\
\hline Threshold value/cut1 & 0.735 & 2.12 & & 0.735 & 2.12 \\
\hline Threshold value/cut2 & 2.138 & 2.14 & & 2.138 & 2.14 \\
\hline Log pseudo likelihood & -89.06 & & & & \\
\hline Wald $\operatorname{chi}^{2}(17)$ & $46.81 * * *$ & & & & \\
\hline Number of observations & 108 & & & & \\
\hline Pseudo $\mathrm{R}^{2}$ & $20.59 \%$ & & & & \\
\hline
\end{tabular}




\section{CONCLUSION}

The purpose of this study was to investigate whether the socioeconomic and institutional factors govern the disparity observed among smallholder farmers in adopting wheat production technology packages, taking in to account three adopter categories of smallholders as low, medium and high in two districts of eastern Ethiopia. The results of this study revealed that large percentages of male-headed households in the study area were found to be low adopters of wheat production technology package. The findings also revealed that higher adopters of the packages were associated with a significant and positive characterization of older household heads compared to the young household heads. Similarly, being a member of a cooperative and having more annual income were found to be major features of the high adopter category of wheat production technologies. On the other hand, farming experiences, number of plots of land, and frequent extension visit contributed towards negatively and significantly lowering adoption categories of the sample households in the contexts of the study districts.

Hence, policy makers, research and technology dissemination experts, development practitioners, and planners should consider the disparity-inducing factors revealed in the study area. Accordingly, consideration of gender-related matters along with gender roles, making smallholder farmers become members of cooperatives, creating opportunities for diversification of smallholder farmers' income sources to advance levels of adoption of agricultural technologies are worth considering.

\section{Acknowledgements}

The authors thank the CASCAPE (Capacity building for scaling up of evidence-based best practices in agricultural production in Ethiopia) project, which was financially supported by The Government of the Netherlands and coordinated by the Royal Netherlands Embassy in Addis Ababa, and hosted by Haramaya University for covering all costs related to the research work.

\section{REFERENCES}

ABEBE, G.K., BIJMAN, J., ASCUCCI, S. and OMTA, O. (2013). Adoption of improved potato variety in Ethiopia: The role of agricultural knowledge and innovation system and smallholder farmers' quality assessment. Journal of Agric. Sys., 122: 22 - 32. doi: http://dx.doi.org/10.1016/j.agsy.2013.07.008

ASFAW, S., KASSIE, M., SIMTOWE, F. and LESLIE, L. (2012). Poverty reduction effects of agricultural technology adoption: a micro-evidence from rural Tanzania. The Journal of Development Studies. 48(9): 1288-1305.

http://dx.doi.org/10.1080/00220388.2012.671475

BACHEWE, F. N., BERHANE, G., MINTEN, B., and TAFFESSE, A. S. (2015). Agricultural growth in Ethiopia (2004-2014): Evidence and drivers. International Food Policy Research Institute (IFRPI),
Ethiopia Strategy Support Program (ESSP), Background Paper Prepared for this Report.

BESHIR, H. (2016). Technical efficiency measurement and their differential in wheat production: The case of smallholder farmers in South Wollo. International Journal of Economics, Business and Finance, Vol. 4, No. 1, January 2016, pp. 1-16, ISSN: 2327-8188 (Online) Available online http://ijebf.com

BIFTU, A. and DIRIBA, B. (2016). Pre-scaling up of bread wheat variety (Danda'a) through FRG/FREG in Bale and West Arsi zones of Oromia national regional state, Ethiopia. Scientific Journal of Crop Science. 5(3): 104-115. Available online at: http://sjournals.com/index.php/SJCS/article/view/2147

BINGXIN, Y., JOSÉ, F. and SINAFIKEH, A. (2011). Cereal Production and Technology Adoption in Ethiopia. Development Strategy and Governance Division. Int. Food Policy Res. Inst. 36p.

CSA (Central Statistical Authority). (2013). Population Projection of Ethiopia for All Regions at Wereda Level from 2014 - 2017. Central Statistical Agency, Addis Ababa, Ethiopia.

CSA (Central Statistical Authority). (2015). Agricultural sample survey 2014/15. Volume I. Report on area and production of major crops for private peasant holdings, meher season. Statistical bulletin 578. Central Statistical Agency, Addis Ababa, Ethiopia.

CSA (Central Statistical Authority). (2016). Agricultural sample survey 2015/16. Volume I. Report on area and production of major crops for private peasant holdings, meher season. Statistical bulletin 584. Central Statistical Agency, Addis Ababa, Ethiopia.

DEGEFU, K. and MENGISTU, K. (2017). Why Do Smallholder Farmers Apply Inorganic Fertilizers below the Recommended Rates? Evidence from Potato Production in Eastern Ethiopia. Adv Crop Sci Tech 5: 265. doi: http://dx.doi.org/10.4172/2329-8863.1000265

DEGEFU, K., MENGISTU, K., NIGUSSIE, D. and FEYISA, H. (2017). Determinants of adoption of wheat production technology Package by smallholder farmers: evidences from eastern Ethiopia. Turkish Journal of Food science and Technology, 5(3): 267 - 274. DOI: https://doi.org/10.24925/turjaf.v5i3.267-274.1041

ENDALE, K. (2011). Fertilizer consumption and agricultural productivity in Ethiopia (No. 003). Available at

http://www.edri.org.et/Resources/Working_Papers/EDRI WP003_Fertilizer_Consumption.pdf

HAGOS, B. G. (2016). Impact of Agricultural technology adoption of smallholder farmers on wheat yield: Emprical evidence from Southern Tigrai state of Ethiopia. J. Agric. Ext. Rural Dev. 8(10): 211-223. DOI: 10.5897/JAERD2016.0786

HIRPA, A., MIRANDA, P.M., TESFAYE, A., LOMMEN, W.J. and LANSINK, A.O. (2010) Analysis of seed potato systems in Ethiopia. American Journal of Potato Research, 87: 537-552. doi: https://doi.org/10.1007/s12230-010-9164-1

KALEB, K. (2017). Determinants of Farmers Access to Information about Improved Wheat Varieties: Case of farmers in major wheat growing regions of Ethiopia. 
International Journal of Research in Agricultural Sciences: 4 (1), ISSN (Online): 2348 - 3997

KALEB, K. and WORKNEH, N. (2016). Analysis of levels and determinants of technical efficiency of wheat producing farmers in Ethiopia. Afr. J. Agric. Res. 11(36): 339 3404.

doi:

https://dx.doi.org/10.5897/AJAR2016.11310

LEGESE, G., LANGYITUO, S.A., MWANGI, W. \& JALETA, M. (2009). Household resource endowment and determinants of adoption of drought tolerant maize varieties: Double-hurdle approach. Contributed paper prepared for presentation at the International Association of Agricultural Economists Conference, Beijing, China, August 16-22:pp.1-22.

LONG, J. S. and FREESE, J. (2014). Regression Models for Categorical Dependent Variables Using Stata. 3rd ed. College Station, TX: Stata Press.

MENGISTU, K. \& BAUER, S. (2011). Determinants of Manure and Fertilizer Applications in Eastern Highlands of Ethiopia. Quarterly Journal of International $\begin{array}{lllr}\text { Agriculture, } & 50 & \text { (3), } & \text { 237-252. }\end{array}$ http://ageconsearch.umn.edu/bitstream/155533/2/2_Kete $\underline{\text { ma.pdf }}$

MENGISTU, K, DEGEFU, K, NIGUSSIE, D. and FEYISA, H. (2016). Determinants of adoption of potato production technology Package by smallholder farmers: evidences from eastern Ethiopia. Review of Agricultural and Applied Economics, 19 (2): 61-68, doi: 10.15414/raae.2016.19.02.03-09

MENGISTU, K and DEGEFU, K. (2017). Adoption Intensity of Inorganic Fertilizers in Maize Production: Empirical Evidence from Smallholder Farmers in Eastern Ethiopia. Journal of Agricultural Science, 9(5): 124 132, doi: http://dx.doi.org/10.5539/jas.v9n5p124

MILLION, T. (2010). Essay on contracts, Risk coping and Technology Adoption in Ethiopia. Department of Economic and Resource Management, Norwegian University of Life Science. Philosophiae Doctor (PhD) Thesis, Department of Economics and Resource Management Norwegian University of Life Sciences, pp 193.

NBE. (2016). Annual Report of the National Bank of Ethiopia (NBE) for the year 2014/15.

NIGUSSIE, D., MENGISTU, K., HAILE, D., WOLE, K., TAMIRU, A. OLKABA, B., SOLOMON, A. \& SAMUEL, T. (2012). Participatory Rural Appraisal for Gurawa, Haramaya, Kombolcha, and Habro Districts (Woredas) of East and West Hararghe Zones in Ethiopia.
OGADA, M. J., MWABU, G. \& MUCHAI, D. (2014). Farm technology adoption in Kenya: a simultaneous estimation of inorganic fertilizer and improved maize variety adoption decisions. Agricultural and food $\begin{array}{lllll}\text { economics, } & 2 & \text { (1), } & 1 . & \text { doi: }\end{array}$ http://dx.doi.org/10.1186/s40100-014-0012-3.

ORTIZ, O., ORREGO, R., PRADEL, W., GILDEMACHER, P., CASTILLO, R., OTINIANO R., GABRIEL J., VALLEJO J., TORRES O., WOLDEGIORGIS G., DAMENE, B., KAKUHENZIRE, R., KASAHIJA, I. and KAHIU, I. (2011). Insights into potato innovation systems in Bolivia, Ethiopia, Peru and Uganda. Agric. System, 114: 73 - 83. doi: http://dx.doi.org/10.1016/j.agsy.2012.08.007

RAO, P.N. \& DEBELA, G. D. (2016.). An Economic inquiry in to the Empirics of the Determinants of demand for technology: an Explorative research. International Journal of Business Quantitative Economics and Applied Management Research, 3 (1), 15 - 23. ISSN No: 23495677

Spielman, D.J., Byerlee, D., Alemu, D. \& Kelemework, D. (2010). Policies to promote cereal intensification in Ethiopia: The search for appropriate public and private roles. Food Policy, 35 (3), 185-194. doi: http://dx.doi.org/10.1016/j.foodpol.2009.12.002

Shiferaw B, Kassie M, Jaleta M, Yirga C. (2014). Adoption of improved wheat varieties and impacts on household food security in Ethiopia. Food Policy. 44: 272-284.

doi: http://dx.doi.org/10.1016/j.foodpol.2013.09.012

StataCorp. (2011). Stata: Release 12. Statistical Software. College Station, TX: StataCorp LP.

Statista. (2017). Global wheat yield per hectare from $2010 / 2011$ to $2025 / 2026$ (in metric tons). https://www.statista.com/statistics/237705/global-wheatproduction

TUFA, A.H., MEUWISSEN, M.P., LOMMEN, W.J., TSEGAYE, A., STRUIK, P.C. and Oude Lansink, A. G. J. M.. (2015) Least-Cost Seed Potato Production in Ethiopia. Potato Research, 58: 277-300. DOI 10.1007/s11540-015-9309-1 